\title{
Vertical Random Vibration Analysis of Track-Subgrade Coupled System in High Speed Railway with Pseudoexcitation Method
}

\author{
Xinwen Yang, Xiaoshan Liu, Shunhua Zhou, Xiaoyun Ma, \\ Jiangang Shen, and Jingchao Zang \\ Key Laboratory of Road and Traffic Engineering of the Ministry of Education, Tongji University, \\ Shanghai 201804, China \\ Correspondence should be addressed to Shunhua Zhou; zhoushh2015@163.com
}

Received 25 February 2016; Revised 16 August 2016; Accepted 20 September 2016

Academic Editor: Carlo Trigona

Copyright (C) 2016 Xinwen Yang et al. This is an open access article distributed under the Creative Commons Attribution License, which permits unrestricted use, distribution, and reproduction in any medium, provided the original work is properly cited.

In order to reduce the ground-borne vibration caused by wheel/rail interaction in the ballastless track of high speed railways, viscoelastic asphalt concrete materials are filled between the track and the subgrade to attenuate wheel/rail force. A high speed train-track-subgrade vertical coupled dynamic model is developed in the frequency domain. In this model, coupling effects between the vehicle and the track and between the track and the subgrade are considered. The full vehicle is represented by some rigid body models of one body, two bogies, and four wheelsets connected to each other with springs and dampers. The track and subgrade system is considered as a multilayer beam model in which layers are connected to each other with springs and damping elements. The vertical receptance of the rail is discussed and the receptance contribution of the wheel/rail interaction is investigated. Combined with the pseudoexcitation method, a solution of the random dynamic response is presented. The random vibration responses and transfer characteristics of the ballastless track and subgrade system are obtained under track random irregularity when a high speed vehicle runs through. The influences of asphalt concrete layer's stiffness and vehicle speed on track and subgrade coupling vibration are analyzed.

\section{Introduction}

Unballasted track has been extensively used in high speed railway construction in China for its high regularity, high stability, and high reliability. But when a high speed train runs on large-rigid unballasted tracks, more noise and vibration are produced than ballasted track, which cause serious impact on the environment, buildings, and residents' living. Many scholars have released a series of studies in view of the vehicle and track coupling vibration and ground vibration. Back in 1995, Knothe and Grassie $[1,2]$ said that one of the major problems of railway engineering dynamics research is to give full consideration to the subgrade system, which should be included into the effective dynamic analysis model of structures. Using the Green function method, Krylov [3] obtained an analytical expression that considers considering the impact of track-subgrade system on ground vibration. Matsuura [4, 5] studied the track-foundation dynamics responses under the simple moving harmonic loads with the green function method in Japanese Shinkansen railway, in addition, considering the layered soil influence on wave propagation. Kaynia et al. [6-8] treated the foundation as a layered viscoelastic half-space body and the rail as EulerBernoulli beam and established a calculation model of the foundation-rail coupling system under moving loads and derived the corresponding dynamic equations using green function. The dynamic behavior of the subgrade under the train load was studied based on the vehicle-track coupling dynamics theory and the finite element method [9-13]. Xu and Cai [14] established a vehicle-track coupling model to study the dynamic behavior of track and subgrade system with modal method. Based on finite element method, the dynamic response of the roadbed under high speed train loads was analyzed, and the effect of the train speed, complex modulus of the subgrade, and vibrating condition of the vehicles were discussed [15]. Based on the theory of Timoshenko beam on elastic foundation and its dynamic solution under a moving load [16], the train-induced reaction forces between 


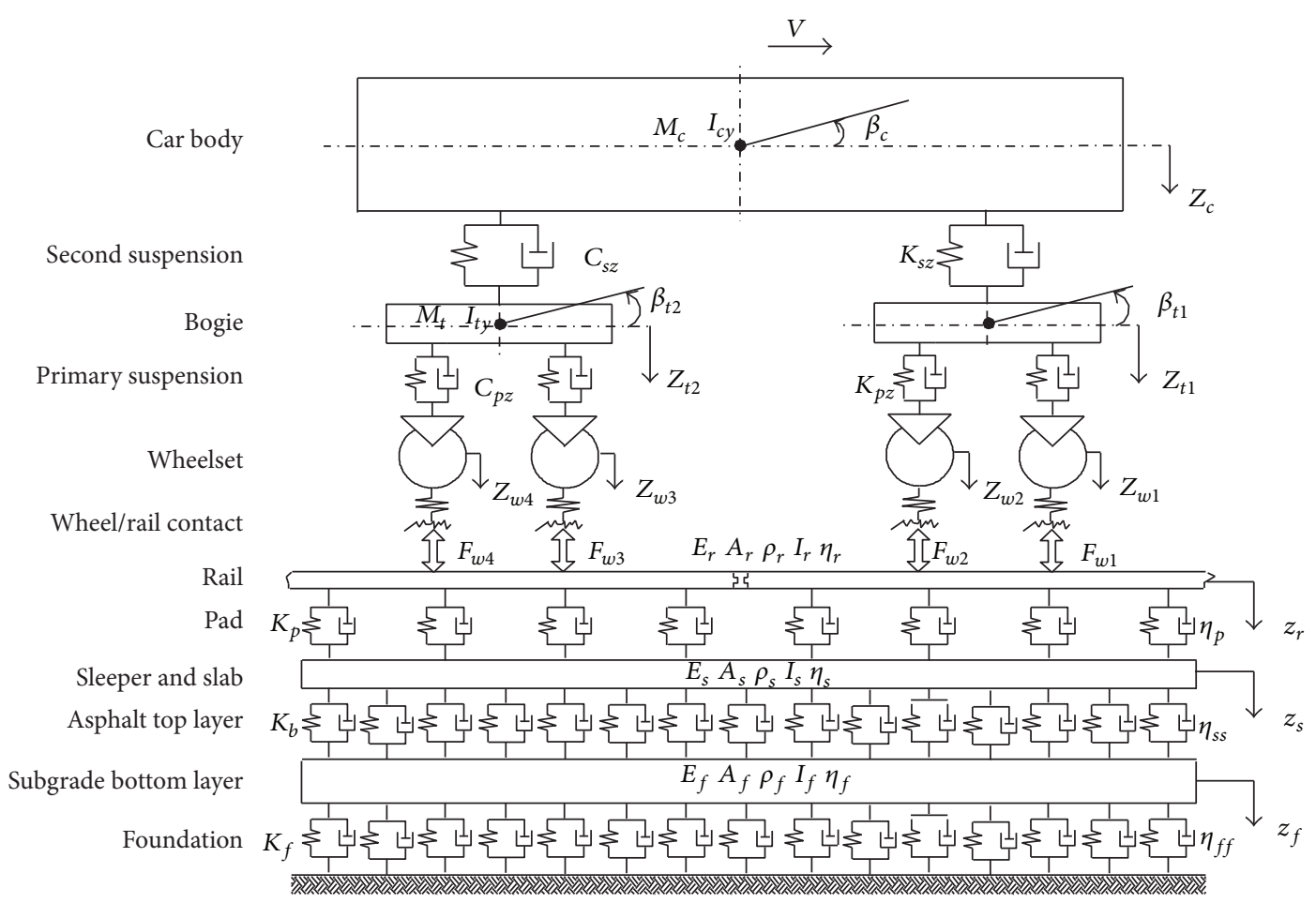

FIGURE 1: Model of vehicle-double block ballastless track-subgrade coupled system.

ground surface and embankment were calculated. Exerting the reaction forces on the ground surface, the corresponding steady-state stresses in the ground were obtained by integrating the basic solution of a moving point load on the surface of an elastic half-space.

The mechanism of track and subgrade coupling vibration caused by trains is relatively complicated, involving problems like vehicles and track parameters matching, wheel/rail contact coupling, track irregularity, and the time-frequency analysis of vibration and foundation coupling. Environmental vibration caused by ballastless tracks of high speed railways is more than the one caused by ballasted tracks, so environmental vibration control of ballastless track is one of the problems in the design and construction of high speed railway. The asphalt concrete layer (ACL) has certain strength and elasticity, which can be used on the track structure to attenuate wheel/rail vibration. In the present paper, a high speed train-track-subgrade vertical coupled dynamic model is developed in the frequency domain. In the proposed model, coupling effects between vehicle and track and between track and subgrade are considered. The full vehicle is represented by a rigid body model of one body, two bogies, and four wheelsets connected to each other with springs and dampers. The track and subgrade system is considered as a multilayer beam model in which layers are connected to each other with springs and damping elements. The receptance of track and subgrade system is discussed and receptance contribution of the wheel/rail system is investigated. Combined with the pseudoexcitation method, a solution of the random dynamical response of the traintrack-subgrade coupling system is presented. The random vibration response and transfer characteristics of ballastless track and subgrade system are obtained under track random irregularity when a high speed vehicle runs through. The influences of the asphalt concrete layer's stiffness and vehicle speed on track and subgrade coupling vibration are analyzed.

\section{The Vehicle-Track-Subgrade Coupling Dynamic Model}

2.1. Physical Model. A vehicle-track-subgrade coupling dynamic model is established based on vehicle-track coupled dynamic theory [17], as is illustrated in Figure 1 (with the four-axle locomotive or vehicle as an example).

In the model, $M_{c}, M_{t}, M_{w}$ are, respectively, the mass of the car body, the frame, and the wheel-set; $I_{c y}$ and $I_{t y}$ are, respectively, the pitch moment of inertia of the car body and the frame; $K_{s z}$ and $C_{s z}$ are, respectively, the vertical stiffness and the damping of the secondary suspension at one side of the frame; $K_{p z}$ and $C_{p z}$ are, respectively, the vertical stiffness and the damping of each primary suspension; $V$ is the vehicle running speed. The material constants of the rail are $E_{r}$, Young's modulus; $G_{r}$, the shear modulus; $A_{r}$, the cross-sectional area; $I_{r}$, the second moment of area; $\rho_{r}$, the density; $\kappa$, the shearing factor, and $\eta_{r}$, the loss factor. The material constants of the slab are $E_{s}$, Young's modulus; $G_{s}$, the shear modulus; $A_{s}$, the cross-sectional area; $I_{s}$, the second moment of area; $\rho_{s}$, the density, and $\eta_{s}$, the loss factor. The material constants of the subgrade layer are $E_{f}$, Young's modulus; $A_{f}$, the cross-sectional area; $I_{f}$, the second moment of area; $\rho_{f}$, the density, and $\eta_{f}$, the loss 
TABLE 1: Degrees of freedom of the system model.

\begin{tabular}{lcc}
\hline System component & \multicolumn{2}{c}{ Type of motion } \\
& Vertical & Pitch \\
\hline Wheelset 1 & $Z_{w 1}$ & $\beta_{w 1}$ \\
Wheelset 2 & $Z_{w 2}$ & $\beta_{w 2}$ \\
Wheelset 3 & $Z_{w 3}$ & $\beta_{w 3}$ \\
Wheelset 4 & $Z_{w 4}$ & $\beta_{w 4}$ \\
Front bogie frame & $Z_{t 1}$ & $\beta_{t 1}$ \\
Real bogie frame & $Z_{t 2}$ & $\beta_{t 2}$ \\
Car body & $Z_{c}$ & $\beta_{c}$ \\
Rail & $z_{r}$ & - \\
Slab & $z_{s}$ & - \\
Subgrade & $z_{f}$ & - \\
\hline
\end{tabular}

factor. $K_{p}, K_{s}$, and $K_{f}$ are, respectively, the stiffness of the rail pad, elastic supporting of track slab, and supporting of subgrade; $\eta_{p}, \eta_{s s}$, and $\eta_{f f}$ are, respectively, the loss factor of the rail pad, elastic supporting of track slab, and supporting of subgrade.

In the vehicle-track-subgrade coupling dynamic model, there are, respectively, the vehicle subsystem, the ballastless track subsystem, and the subgrade subsystem from top to bottom, as is shown in Figure 1. In the vehicle subsystem, the car body, the frame, and the wheelset are assumed as rigid bodies, and both the car body and the frame have two DOFs (degrees of freedom) of nodding and vertical movement and the wheelset has only vertical movement, so the whole vehicle subsystem has 10 DOFs, which are listed in Table 1. The connections between car body and two bogies are the second suspension, and the connection between each bogie and two wheelsets is the primary suspension.

The double-block ballastless track system on the subgrade is mainly composed of rails, high elastic fasteners, doubleblock sleepers improved with truss reinforcing steel bars, slabs, and the rigid supporting layers under slabs. The rail is modeled as an infinite Timoshenko beam with continuous elastic discrete supports, which has one DOF of vertical motion. And the double-block sleepers, slabs, and supporting layers are considered as a whole called slab, modeled as a freefree Euler beam, which has a DOF of vertical motion. And the rail is vertically connected with the sleepers by viscous damping and linear springs.

The subgrade subsystem consists of the surface layer of the bed, the bottom layer of the bed, and the subgrade layer. The surface layer of the bed which is asphalt concrete layer regarded as an elastic cushion is modeled as linear springs and viscous damping elements. And the bottom layer of the bed is regarded as a free-free Euler beam with one DOF of vertical motion. And the subgrade layer is simulated by linear springs and viscous damping elements. Therefore, the connections between the track bed and the bottom layer of the bed and those between the bottom layer of the bed and the subgrade are linear springs and viscous damping elements.

An interaction between the vehicle subsystem and the ballastless track subsystem is the wheel/rail force. The vertical wheel/rail interaction force is approximately calculated using the Hertz contact theory. The coupling effect between the ballastless track subsystem and the subgrade subsystem can be coordinated by the interaction force between the slab and the subgrade surface.

\subsection{Equations of Motion of Track-Subgrade System}

2.2.1. The Rail. The rail is considered as an infinite Timoshenko beam, and its differential equations of motion in the frequency domain are

$$
\begin{aligned}
& -\rho_{r} A_{r} \omega^{2} z_{r}(x)+G_{r} A_{r} \kappa\left(\varphi^{\prime}(x)-z_{r}^{\prime \prime}(x)\right) \\
& =\sum_{j=1}^{N_{w}} F_{w j} \delta\left(x-x_{w j}\right)-\sum_{i=1}^{N_{p}} f_{p h i} \delta\left(x-x_{p i}\right) \\
& -\rho_{r} I_{r} \omega^{2} \varphi(x)+G_{r} A_{r} \kappa\left(\varphi(x)-z_{r}^{\prime}(x)\right)-E_{r} I_{r} \varphi^{\prime \prime}(x) \\
& =0,
\end{aligned}
$$

where $z_{r}(x)$ is the vertical displacement of the rail and $\varphi(x)$ is the rotate angular of the cross section of the rail; $F_{w j}$ denotes the amplitude of the force applied on the rail by the $j$ th wheel and $\omega$ is the angular frequency; $x_{p i}$ is the longitudinal coordinate of the discretely distributed rubber pads under the rail and $i$ is the ordinal number of the rubber pads; $N_{p}$ is the total number of the rubber pads; $x_{w j}$ is the longitudinal coordinate of the wheels, $j$ is the ordinal number of the wheels, and $N_{w}$ is the total number of the wheels; and $\delta(\cdot)$ is the Dirac-delta function. $f_{p h i}$ denotes the reaction of the supporting force applied on the rail by the $i$ th rail pad, as is given by

$$
f_{p h i}=K_{p i}\left(z\left(x_{p i}\right)-z\left(x_{p i}\right)\right),
$$

where $K_{p i}$ is the stiffness of the $i$ th rail pad.

The vertical displacement of any point of the rail in $x$ direction is

$$
z_{r}(x)=\sum_{j=1}^{M_{w}} F_{w j} \alpha_{r}\left(x, x_{w j}\right)-\sum_{i=1}^{N_{p}} f_{p h i} \alpha_{r}\left(x, x_{p i}\right),
$$

where $\alpha_{r}\left(x, x_{w j}\right)$ and $\alpha_{r}\left(x, x_{p i}\right)$ are the dynamic flexibility of the rail at position $x$ due to a unit force acting at positions $x_{w j}$ and $x_{p i}$, respectively, and the dynamic flexibility of the rail is generally given by

$$
\begin{aligned}
& \alpha_{r}\left(x_{1}, x_{2}\right)=u_{1} e^{-i k_{1}\left|x_{1}-x_{2}\right|}+u_{2} e^{-k_{2}\left|x_{1}-x_{2}\right|} \\
& k_{1}=\left(\frac{\omega}{\sqrt{2}}\right)\left\{\left[\left(\frac{\rho_{r}}{E_{r}\left(1+\eta_{r}\right)}-\frac{\rho_{r}}{G_{r} \kappa_{r}}\right)^{2}\right.\right. \\
& \left.+\frac{4 \rho_{r} A_{r}}{E_{r}\left(1+\eta_{r}\right) I_{r} \omega^{2}}\right]^{1 / 2}+\left(\frac{\rho_{r}}{E_{r}\left(1+\eta_{r}\right)}\right. \\
& \left.\left.+\frac{\rho_{r}}{G_{r} \kappa_{r}}\right)\right\}^{1 / 2}
\end{aligned}
$$




$$
\begin{aligned}
k_{2}=\left(\frac{\omega}{\sqrt{2}}\right)\left\{\left[\left(\frac{\rho_{r}}{E_{r}\left(1+\eta_{r}\right)}-\frac{\rho_{r}}{G_{r} \kappa_{r}}\right)^{2}\right.\right. \\
\left.+\frac{4 \rho_{r} A_{r}}{E_{r}\left(1+\eta_{r}\right) I_{r} \omega^{2}}\right]^{1 / 2}-\left(\frac{\rho_{r}}{E_{r}\left(1+\eta_{r}\right)}\right. \\
\left.\left.+\frac{\rho_{r}}{G_{r} \kappa_{r}}\right)\right\}^{1 / 2} \\
u_{1}=\frac{i}{E_{r}\left(1+\eta_{r}\right) I_{r} G_{r} \kappa_{r}} \\
. \frac{\rho_{r} I_{r} \omega^{2}-G_{r} \kappa_{r} A_{r}-E_{r}\left(1+\eta_{r}\right) I_{r} k_{1}^{2}}{2 A_{r} k_{1}\left(k_{1}^{2}+k_{2}^{2}\right)} \\
u_{2}=\frac{1}{E_{r}\left(1+\eta_{r}\right) I_{r} G_{r} \kappa_{r}} \\
. \frac{\rho_{r} I_{r} \omega^{2}-G_{r} \kappa_{r} A_{r}-E_{r}\left(1+\eta_{r}\right) I_{r} k_{2}^{2}}{2 A_{r} k_{2}\left(k_{1}^{2}+k_{2}^{2}\right)} .
\end{aligned}
$$

2.2.2. The Track Slab. The track slab is considered as a finite free-free Euler-Bernoulli beam, and its differential equation of vibration in the frequency domain is

$$
\begin{aligned}
- & \omega^{2} \rho_{s} A_{s} z_{s}(x)+E_{s} I_{s} z_{s}^{\prime \prime \prime \prime}(x) \\
= & \sum_{i=1}^{N_{p}} f_{p i} \delta\left(x-x_{p i}\right)-\sum_{p=1}^{N_{s}} f_{s p} \delta\left(x-x_{s p}\right),
\end{aligned}
$$

where the material constants of the slab are $E_{s}$, Young's modulus; $G_{s}$, the shear modulus; $A_{s}$, the cross-sectional area; $I_{s}$, the second moment of area; $\rho_{s}$, the density; and $\eta_{s}$, the loss factor. $z_{s}, x_{p i}$, and $x_{s j}$ are, respectively, the vertical displacement of the slabs, the longitudinal coordinate at the fasteners, and the longitudinal coordinate at the supporting points of the slabs; $f_{p i}$ is the interaction force between the rail and the slab, and $f_{s j}$ is the interaction force between the slab and the subgrade; $N_{p}$ and $N_{s}$ are, respectively, the total numbers of the supporting points of fasteners and slabs:

$$
f_{s p}=K_{s}\left(u_{s}\left(x_{s p}\right)-u_{b}\left(x_{s p}\right)\right) \text {. }
$$

Because there is a rigid connection between the sleeper and the slab in the double-block ballastless track, the effect of the inertia force produced by sleeper blocks vibration on the vibration of track slabs is important, as is shown in Figure 2.

Assuming that $z_{r}(x, t)$ and $z_{s}(x, t)$ denote, respectively, the vertical displacement of the rail and the track slab on the rail pad in the time domain, the inertia force produced by the sleeper block is

$$
f_{\text {sleep }}=-M_{s} \frac{\partial^{2}}{\partial t^{2}} z_{s}(x, t)
$$

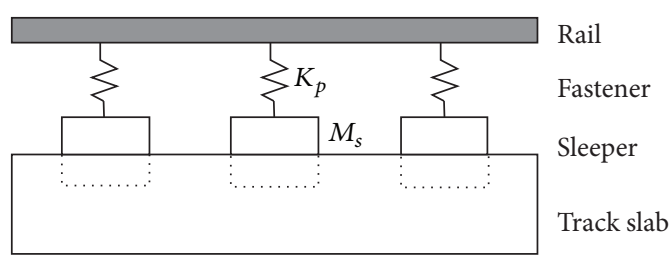

FIgURE 2: Combination of sleeper and slab of twin-block ballastless track structure.

So $f_{p h i}$ is the force applied to the track slab by the rail on the $i$ th pad, as is given by

$$
f_{p h i}=K_{p}\left(z_{r}\left(x_{p h i}\right)-z_{s}\left(x_{p h i}\right)\right)-M_{s} \omega^{2} z_{s}\left(x_{p h i}\right),
$$

where $K_{p}$ is the pad stiffness and $M_{s}$ is the sleeper block mass.

The vertical displacement of any point of the track slab in $x$ direction is

$$
z_{s}(x)=\sum_{i=1}^{N_{p}} f_{p i} \alpha_{s}\left(x, x_{p i}\right)-\sum_{p=1}^{N_{s}} f_{s p} \alpha_{s}\left(x, x_{s p}\right),
$$

where $\alpha_{s}\left(x, x_{p i}\right)$ and $\alpha_{s}\left(x, x_{s p}\right)$ are, respectively, the dynamic flexibility of the track slab at position $x$ due to a unit harmonic force acting at positions $x_{p i}$ and $x_{s p}$, and the dynamic flexibility of the track slab is generally [18]

$$
\alpha_{s}\left(x_{1}, x_{2}\right)=\sum_{n=1}^{\mathrm{NMS}} \frac{W_{n}\left(x_{2}\right) W_{n}\left(x_{1}\right)}{\omega_{n}^{2}-\omega^{2}}
$$

where $\omega_{s n}=\beta_{n}^{2} \sqrt{E_{s} I_{s} / \rho_{s} A_{s}}$ is the $n$th mode frequency of the slab and $\beta_{n}$ is the wavenumber. NMS is the modal number of the track slabs in calculation. $W_{n}(x)$ is the modal shape function of the free-free Euler beam.

2.2.3. The Subgrade Layer. The subgrade layer is considered as an infinite Euler-Bernoulli beam, and its differential equation of vibration in the frequency domain is

$$
\begin{aligned}
- & \omega^{2} \rho_{f} A_{f} z_{f}(x)+E_{f} I_{f} z_{f}^{\prime \prime \prime \prime}(x) \\
= & \sum_{p=1}^{N_{s}} f_{s p} \delta\left(x-x_{s p}\right)-\sum_{q=1}^{N_{f}} f_{f q} \delta\left(x-x_{f q}\right),
\end{aligned}
$$

where $z_{f}, x_{s h p}$, and $x_{f h q}$ are, respectively, the vertical displacement of the subgrade layer, the longitudinal coordinate at the supporting points of the slabs, and the subgrade layer; $f_{s h}$ is the interaction force between the slab and the subgrade layer, and $f_{f q}$ is the interaction force between the subgrade layer and the subgrade; $N_{f}$ and $N_{s}$ are, respectively, the total numbers of the supporting points of the subgrade layer and the slabs:

$$
f_{f q}=K_{f} z_{f}\left(x_{f q}\right) .
$$

The vertical displacement of any point of the subgrade layer in $x$ direction is

$$
z_{f}(x)=\sum_{p=1}^{N_{s}} f_{s p} \alpha_{f}\left(x, x_{s p}\right)-\sum_{q=1}^{N_{f}} f_{f q} \alpha_{f}\left(x, x_{f q}\right),
$$


where $\alpha_{f}\left(x, x_{s p}\right)$ and $\alpha_{f}\left(x, x_{f q}\right)$ are, respectively, the dynamic flexibility of the track slab, denoting the displacement response at position $x$ due to a unit harmonic force acting at positions $x_{s p}$ and $x_{f q}$, and the dynamic flexibility of the track slab is generally

$$
\alpha_{f}\left(x_{1}, x_{2}\right)=C_{1} e^{\lambda_{1}\left|x_{1}-x_{2}\right|}+C_{2} e^{\lambda_{2}\left|x_{1}-x_{2}\right|},
$$

where $C_{1}$ and $C_{2}$ are complex constants [19].

All the above equations, except for the dynamic flexibility of rail and slab, do not have explicit damping. But actually the bending stiffness of beam and the stiffness of spring are in complex stiffness form, that is, $G_{r}\left(1+i \eta_{r}\right), E_{r} I_{r}\left(1+i \eta_{r}\right)$, $E_{s} I_{s}\left(1+i \eta_{s}\right), E_{f} I_{f}\left(1+i \eta_{b}\right), K_{p}\left(1+i \eta_{p}\right), K_{s}\left(1+i \eta_{s s}\right)$, and $K_{f}(1+$ $\left.i \eta_{f f}\right)$, where $\eta_{r}, \eta_{s}, \eta_{f}, \eta_{p}, \eta_{s s}$, and $\eta_{f f}$ are, respectively, the loss factors of rail, track slab, subgrade, rail pad, elastic supporting of track slab, and supporting of subgrade.

Assuming that the amplitude of the dynamic wheel/rail force induced by track irregularity is $\{P(\Omega)\}$, the displacement amplitude of any point of track and subgrade system, $\left\{z_{\mathrm{TS}}(\Omega)\right\}$, can be obtained by

$$
\left\{z_{\mathrm{TS}}(\Omega)\right\}=\left[\alpha_{\mathrm{TS}}\right]\{P(\Omega)\},
$$

where $\left[\alpha_{\mathrm{TS}}\right]$ is the dynamic flexibility of track-subgrade system at the position of the wheelset, which is composed of dynamic flexibility of track-subgrade system structure, $\alpha_{r}, \alpha_{s}$, and $\alpha_{f}$.

2.3. Equations of Motion of Vehicle. The vehicle system is composed of car body, two bogies, and four wheelsets for high speed train. The equation of movement of the vehicle system is [19]

$$
\begin{aligned}
& {\left[M_{V}\right]\left\{\ddot{z}_{V}(t)\right\}+\left[C_{V}\right]\left\{\dot{z}_{V}(t)\right\}+\left[K_{V}\right]\left\{z_{V}(t)\right\}} \\
& \quad=\left\{Q_{V}(t)\right\}
\end{aligned}
$$

where $\left[M_{V}\right],\left[C_{V}\right]$, and $\left[K_{V}\right]$ are, respectively, the generalized mass matrix, generalized damping matrix, and generalized stiffness matrix of the vehicle system; $\left\{z_{V}(t)\right\},\left\{\dot{z}_{V}(t)\right\}$, and $\left\{\ddot{z}_{V}(t)\right\}$ are, respectively, the generalized displacement vector, generalized velocity vector, and generalized acceleration vector of the vehicle system; and $\left\{Q_{V}(t)\right\}$ is the generalized dynamic force vector of the vehicle system:

$$
\begin{aligned}
& {\left[M_{V}\right]=\operatorname{diag}\left\{\begin{array}{llllllllll}
M_{C} & J_{C} & M_{t} & M_{t} & J_{t} & J_{t} & M_{w 1} & M_{w 2} & M_{w 3} & M_{w 4}
\end{array}\right\}}
\end{aligned}
$$

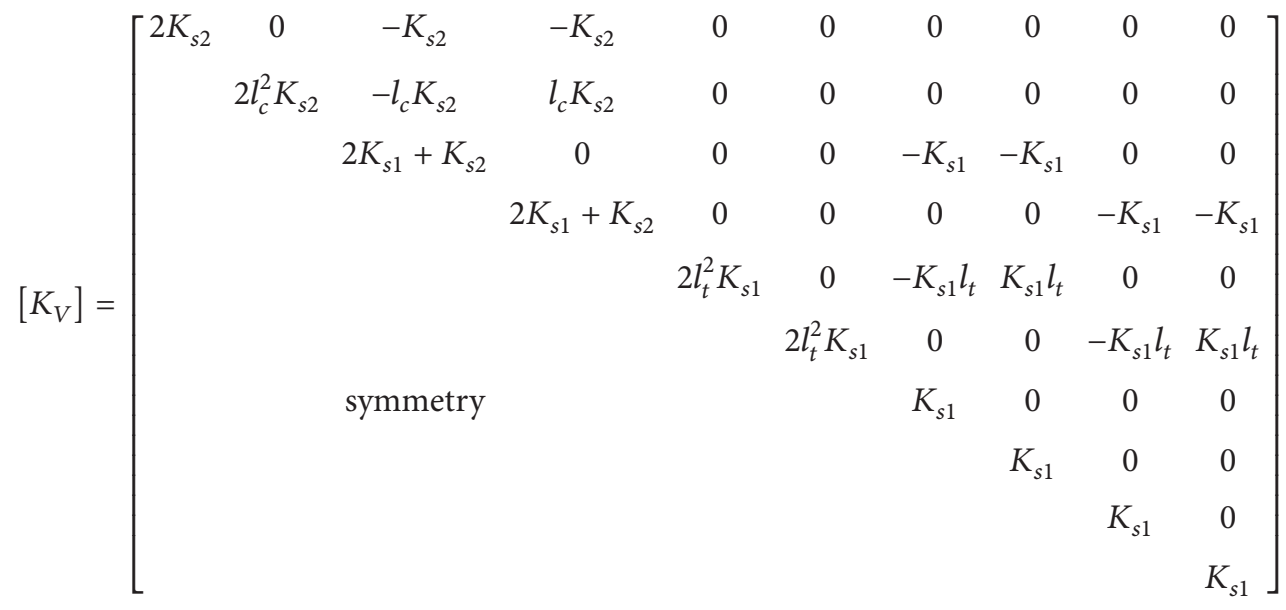

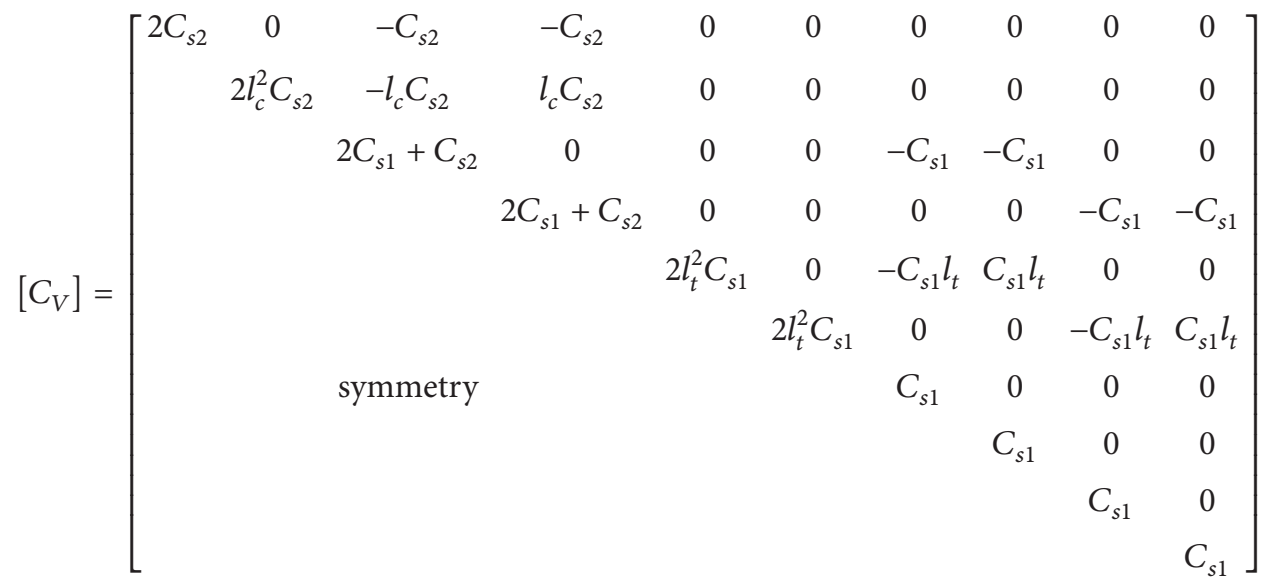




$$
\begin{aligned}
& \left\{z_{V}(t)\right\}=\left\{z_{c}(t) \quad \varphi_{c}(t) \quad z_{t 1}(t) \quad z_{t 2}(t) \varphi_{t 1}(t) \quad \varphi_{t 2}(t) \quad z_{w 1}(t) z_{w 2}(t) z_{w 3}(t) z_{w 4}(t)\right\}^{T}
\end{aligned}
$$

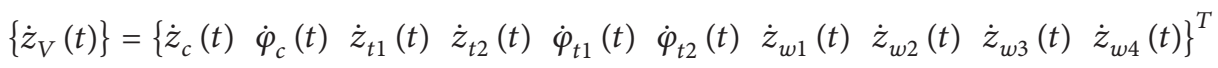

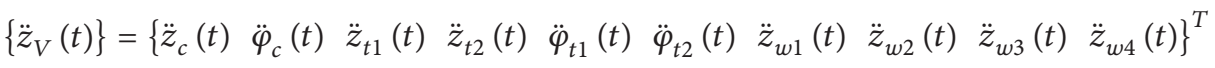

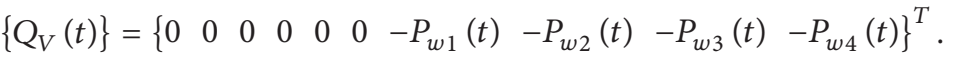

Assuming $\{P(\Omega)\}$ as the amplitude of dynamic wheel/rail force induced by track irregularity yields, the amplitude of wheel displacement $\left\{z_{w}(\Omega)\right\}$ is

$$
\left\{z_{w}(\Omega)\right\}=\left[\alpha_{w}\right]\{P(\Omega)\},
$$

where $\left[\alpha_{w}\right]=[H]\left[\alpha_{V}\right][H]^{T}$ is the dynamic flexibility of the vehicle at the wheel/rail contact point and $\Omega$ is spatial frequency $(\mathrm{rad} / \mathrm{m}) .\left[\alpha_{V}\right]$ is the dynamic flexibility of the vehicle.

2.4. The Wheel/Rail Interaction. The wheel/rail interaction force is described by

$$
\{P(\Omega)\}=\left(\left[\alpha_{W}\right]+\left[\alpha_{\mathrm{TS}}\right]+\left[\alpha_{\Delta}\right]\right)^{-1}\{\Delta z(\Omega)\},
$$

where $\left[\alpha_{\Delta}\right]$ is the dynamic flexibility of the wheel/rail contact spring; $\left[\alpha_{\Delta}\right]=1 / k_{H}$. Since the dynamic displacements are small, $k_{H}$ is linearized wheel/rail contact stiffness according to the preload between the wheel and the rail and their radii of curvature. $\Delta z(\Omega)$ is the relative displacement (track random irregularity) between the wheel and the rail and can be obtained by using pseudoexcitation method [20-23]. $\{P(\Omega)\}$ is the amplitude of the wheel/rail force induced by track irregularity; then the wheel/rail force in time domain can be expressed as

$$
\{P(t)\}=\{P(\Omega)\} e^{i \Omega t} .
$$

There are generally two kinds of excitation input methods of analyzing the vehicle-track coupling vibration. One is fixed-point excitation, and the other is moving-point excitation. For the former, supposing that the vehicle and track are fixed, the track irregularity excitation moves backward at a certain speed. For the latter, the vehicle runs on the track with random irregularity at a certain speed. In the present paper, the fixed-point excitation method is used.

When a train runs on an irregular track, it can be assumed that the different wheels on the same rail are excited by the same track irregularity, but there will be time delay among different wheels, $t_{1}, t_{2}, \ldots, t_{N}$. Track random excitation $\{\Delta z(t)\}$ at wheelsets $N$ is

$$
\{\Delta z(t)\}=\left\{\begin{array}{c}
\Delta z_{1}(t) \\
\Delta z_{2}(t) \\
\vdots \\
\Delta z_{N}(t)
\end{array}\right\}=\left\{\begin{array}{c}
\Delta z_{1}\left(t-t_{1}\right) \\
\Delta z_{2}\left(t-t_{2}\right) \\
\vdots \\
\Delta z_{N}\left(t-t_{N}\right)
\end{array}\right\},
$$

where $\Delta z(t)$ is the history value of vertical track random irregularity; $t_{j}(j=1,2, \ldots, N)$ is the time delay of each wheel; $t_{j}=\left(a_{j}-a_{1}\right) / v ; a_{j}$ is the longitudinal coordinate of the $j$ th wheelset at the time $t=0$, and $a_{1}$ is the longitudinal coordinate of the first wheelset. $\{\Delta z(t)\}$ can be regarded as a generalized single excitation. If the power spectrum density function of $\Delta z(t)$ is $S_{v}(\Omega)$, the pseudoexcitation of vertical track random irregularity can be expressed as

$$
\Delta \bar{z}(t)=\sqrt{S_{v}(\Omega)} e^{i \Omega t}
$$

Then the pseudoexcitation corresponding to (21) is

$$
\begin{aligned}
\{\Delta \bar{z}(t)\} & =\left\{\begin{array}{c}
\Delta \bar{z}_{1}\left(t-t_{1}\right) \\
\Delta \bar{z}_{2}\left(t-t_{2}\right) \\
\vdots \\
\Delta \bar{z}_{N}\left(t-t_{N}\right)
\end{array}\right\}=\left\{\begin{array}{c}
e^{-i \Omega t_{1}} \\
e^{-i \Omega t_{2}} \\
\vdots \\
e^{-i \Omega t_{N}}
\end{array}\right\} \sqrt{S_{v}(\Omega)} e^{i \Omega t} \\
= & \{\Delta \bar{z}(\Omega)\} e^{i \Omega t}
\end{aligned}
$$

where $\{\Delta \widetilde{z}(\Omega)\}$ is the harmonic irregularity amplitude of the pseudoexcitation of vertical track random irregularity.

$$
\{\Delta \bar{z}(\Omega)\}=\left\{\begin{array}{c}
e^{-i \Omega t_{1}} \\
e^{-i \Omega t_{2}} \\
\vdots \\
e^{-i \Omega t_{N}}
\end{array}\right\} \sqrt{S_{v}(\Omega)}
$$

Replacing $\{\Delta z(\Omega)\}$ in (19) with $\{\Delta \widetilde{z}(\Omega)\}$ in (24), we can have that

$$
\{\widetilde{P}(\Omega)\}=\frac{\{\Delta \widetilde{z}(\Omega)\}}{\left(\left[\alpha_{W}\right]+\left[\alpha_{\mathrm{TS}}\right]+\left[\alpha_{\Delta}\right]\right)},
$$

where $\{\widetilde{P}(\Omega)\}$ is the amplitude of pseudodynamic wheel/rail force corresponding to pseudoexcitation $\{\Delta \widetilde{z}(\Omega)\}$. By solving (25), the amplitude of pseudodynamic wheel/rail force induced by track irregularity can be obtained. According to the pseudoexcitation method, the power spectral density of the dynamic wheel/rail force, $S_{P P}(\Omega)$, is given as follows:

$$
S_{P P}(\Omega)=\{\widetilde{P}(\Omega)\}^{*} \cdot\{\widetilde{P}(\Omega)\}^{T}
$$




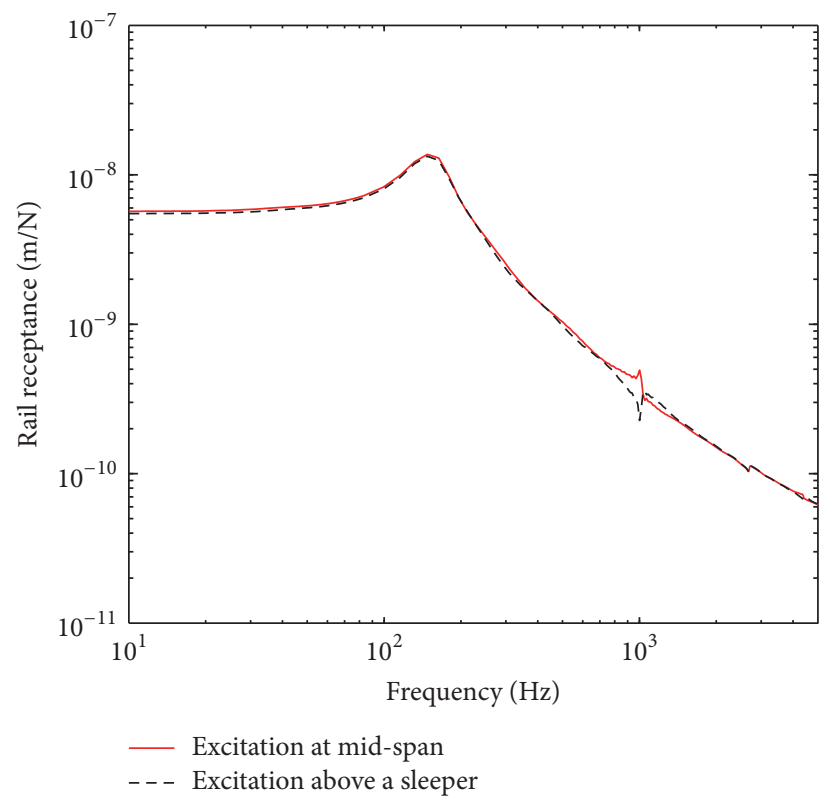

(a) The present model

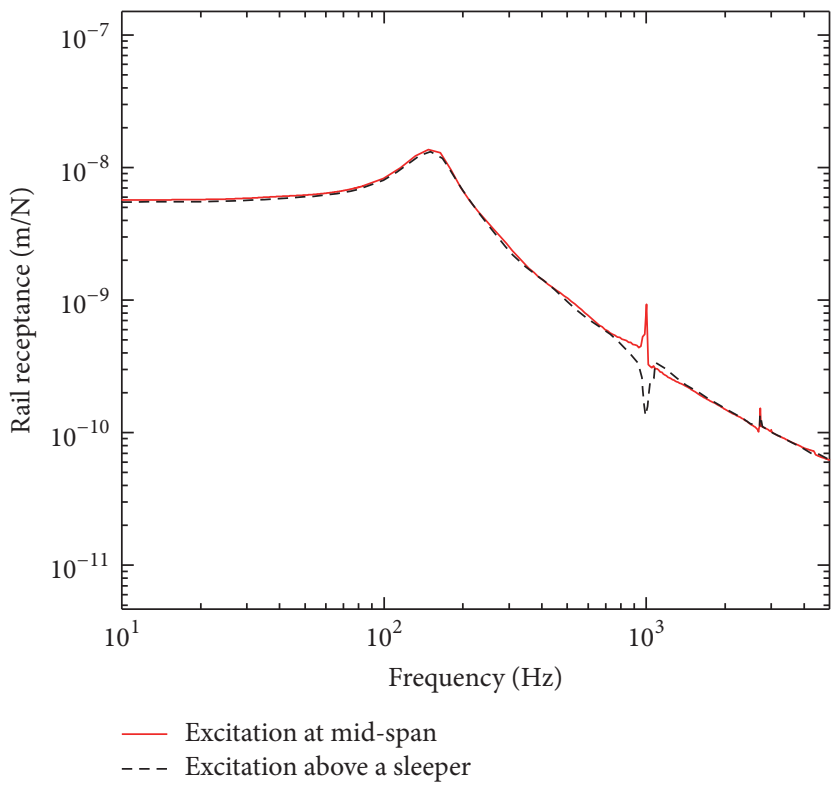

(b) FEM model

FIGURE 3: Vertical receptance of the rail.

where $\{\widetilde{P}(\Omega)\}^{*}$ and $\{\widetilde{P}(\Omega)\}^{T}$ are the conjugated matrix and transfer matrix of $\{\widetilde{P}(\Omega)\}$, respectively.

According to (19) and (26), the power spectral density of the dynamic wheel/rail force can be obtained. Through (15) and (18), the dynamic response of any point of vehicle-tracksubgrade coupling system can be calculated.

\section{Results and Discussion}

3.1. The Rail Receptance. The receptance of the structure is the dynamic response of each part of the structure under a unit force, also known as the dynamic flexibility of the structure. It is generally in complex form, of which the amplitudefrequency and phase-frequency curves reflect the transfer characteristics of the structure dynamic response. The amplitude of the mobility is usually named as the receptance, which can be divided into displacement, velocity, and acceleration receptance. In order to validate the effectiveness of the proposed method, a numerical simulation for calculating the mobility of double-block ballastless track and subgrade coupling system is set up using the finite element analysis software ANSYS, in which there are two slabs with a length of $12.5 \mathrm{~m}$ each, a rail, and a subgrade layer with a length of $25 \mathrm{~m}$. A unit harmonic force is applied to the rail both at midspan and above sleepers, and the comparisons of the vertical receptance of the rail at the excitation point are shown in Figure 3.

In Figure 3, the vertical receptance of the double-block ballastless track is depicted, both at mid-span and above sleeper. There are three peaks in the vertical receptance. The first one corresponds to the vertical vibration mode of the pad, at $157 \mathrm{~Hz}$; the second one corresponds to the first vertical pined-pined resonance of the rail which is related to the rail discrete support, at $1059 \mathrm{~Hz}$; the last one is the high frequency vibration of the rail at $2740 \mathrm{~Hz}$. It can also be seen from Figures 3(a) and 3(b) that the peak frequencies of the results of the proposed model are basically consistent with those of the finite element method.

The wheel/rail contact point applied at the mid-span of the adjacent fasteners, the total receptance, and phase curves are shown in Figure 4.

From Figure 4, it can be seen that, in the frequency range of $1 \sim 32 \mathrm{~Hz}$, the receptance of the wheel is much larger than that of the rail and wheel/rail contact, and the dynamic flexibility amplitude and phase of wheel/rail system are almost equivalent to the flexibility of the wheel, indicating that in the range of $1 \sim 32 \mathrm{~Hz}$ the receptance of the wheel plays the main role in the whole flexibility of the wheel/rail system; in the range of $32 \sim 60 \mathrm{~Hz}$, because the receptance of the wheel is in the same level with that of the rail, the dynamic flexibility of wheel/rail system is mainly decided both by rail and by wheel, and, at $45 \mathrm{~Hz}$, the total receptance has a local minimum; in the range of $60 \sim 277 \mathrm{~Hz}$, the receptance of the rail is larger than that of the wheel and wheel/rail contact, so the dynamic flexibility amplitude and phase of wheel/rail system are mostly decided by the rail, and, at $200 \mathrm{~Hz}$, the dynamic flexibility amplitude of wheel/rail system has a peak value; in the range of $277 \sim 1000 \mathrm{~Hz}$, both the rail and the wheel play a main role in the dynamic flexibility of wheel/rail system; above $100 \mathrm{~Hz}$, the wheel/rail contact receptance plays a main role in the dynamic flexibility of wheel/rail system.

3.2. Random Vibration Analysis of the System. When the train is running at the speed of $300 \mathrm{~km} / \mathrm{h}$, the rack random irregularity will lead to the random vibration of vehicle-tracksubgrade coupling system. The track random irregularity spectrum curve is shown in Figure 5, which is the superposition of the results between track random irregularity 


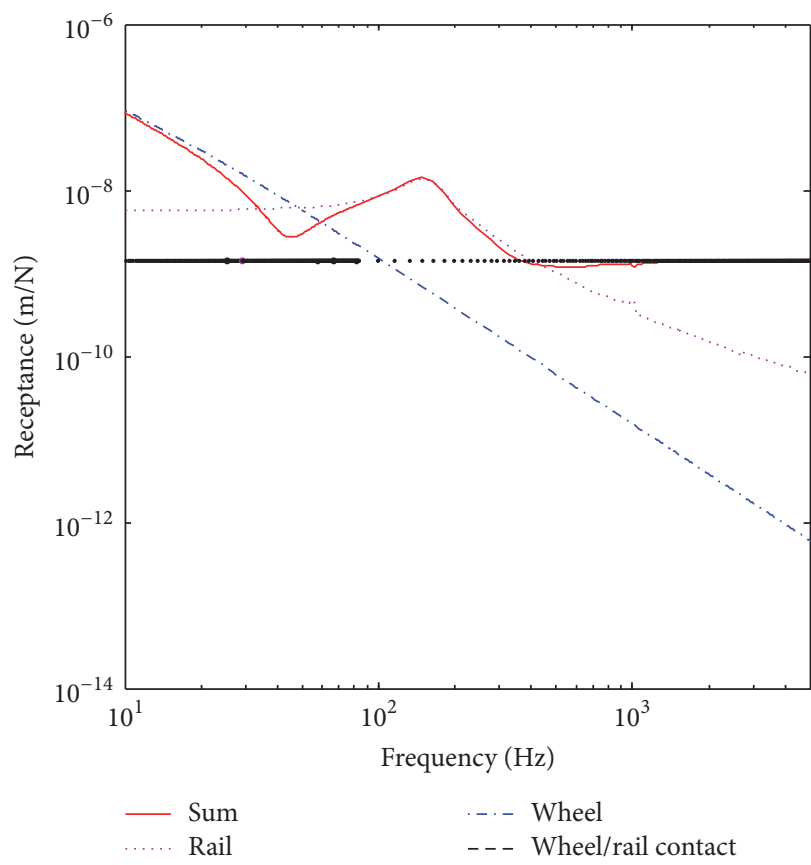

(a) Receptance

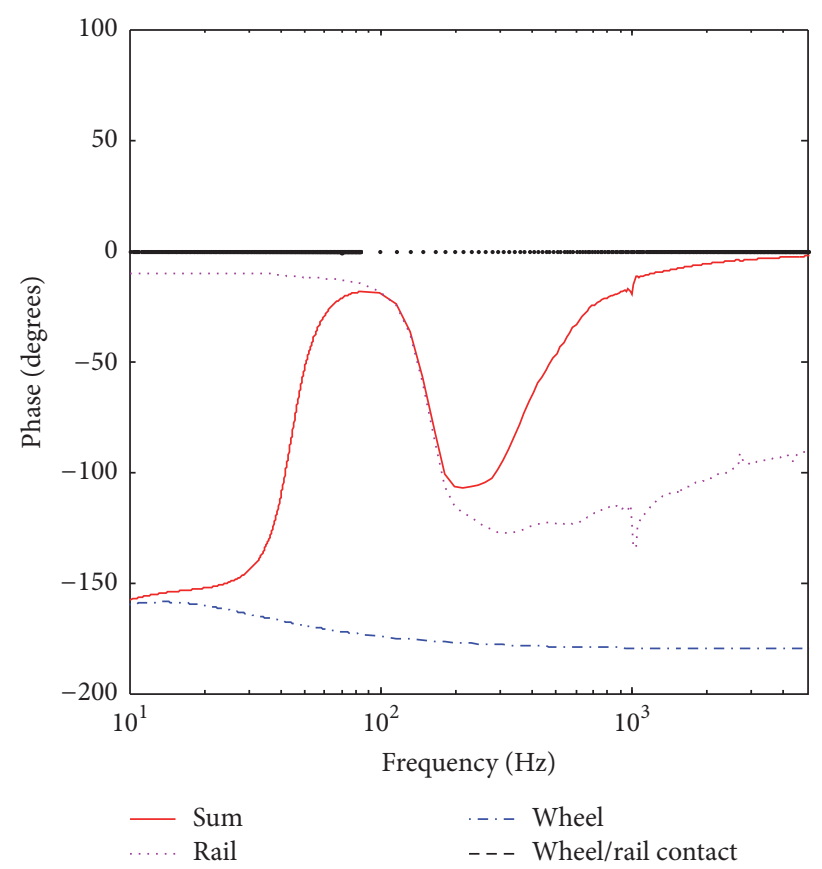

(b) Phase

FIGURE 4: Displacement receptance contribution of the wheel/rail system.

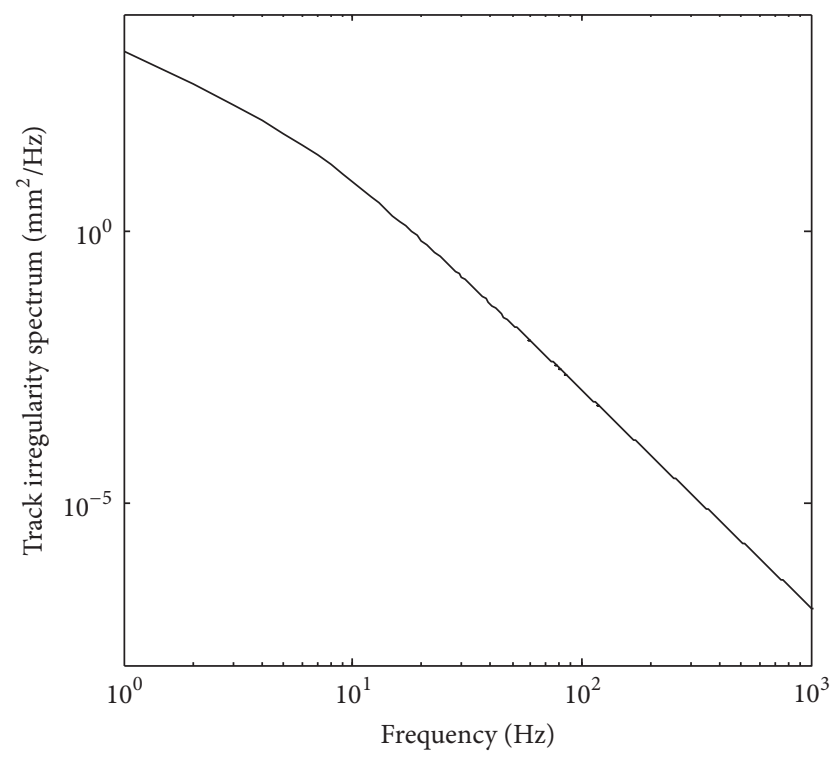

FIGURE 5: Track random irregularity.

and rail surface roughness from China's high speed railway measurement. The wheel/rail force is shown in Figure 6. Figure 7 demonstrates the vertical vibration acceleration power spectrum curve of the rail at the excitation point, and the vertical vibration acceleration power spectrum curves of the slab and the subgrade at the cross section of excitation are, respectively, shown in Figures 8 and 9.

From Figure 6, it can be seen that the wheel/rail interaction forces caused by track random irregularity are concentrated in the range of $10 \sim 1000 \mathrm{~Hz}$ and the amplitude energy

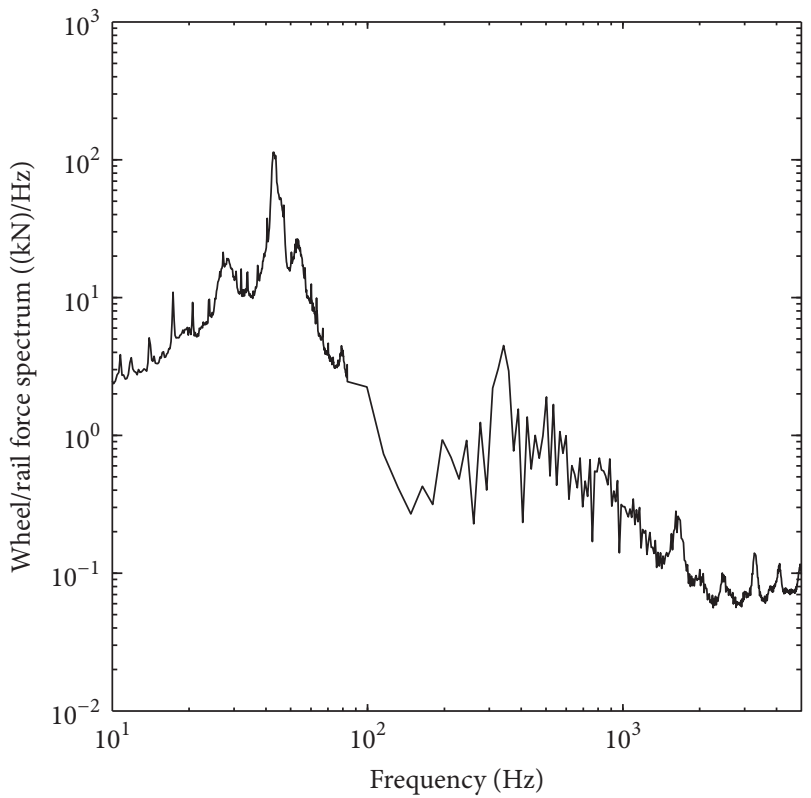

FIgURE 6: The amplitude spectrum of wheel/rail force.

of wheel/rail force reaches maximum at $54 \mathrm{~Hz}$ and second large at $380 \mathrm{~Hz}$. Above $1000 \mathrm{~Hz}$, the wheel/rail force has some peaks but the corresponding vibration energy is small. From Figure 7, it can be seen that the vibration acceleration power spectrum density of the rail caused by track random irregularity has three obvious peaks in the range of $30 \sim 1000 \mathrm{~Hz}$, respectively, at $43 \mathrm{~Hz}, 341.2 \mathrm{~Hz}$, and $502.3 \mathrm{~Hz}$, where the corresponding wavelength is, respectively, $2 \mathrm{~m}$, 


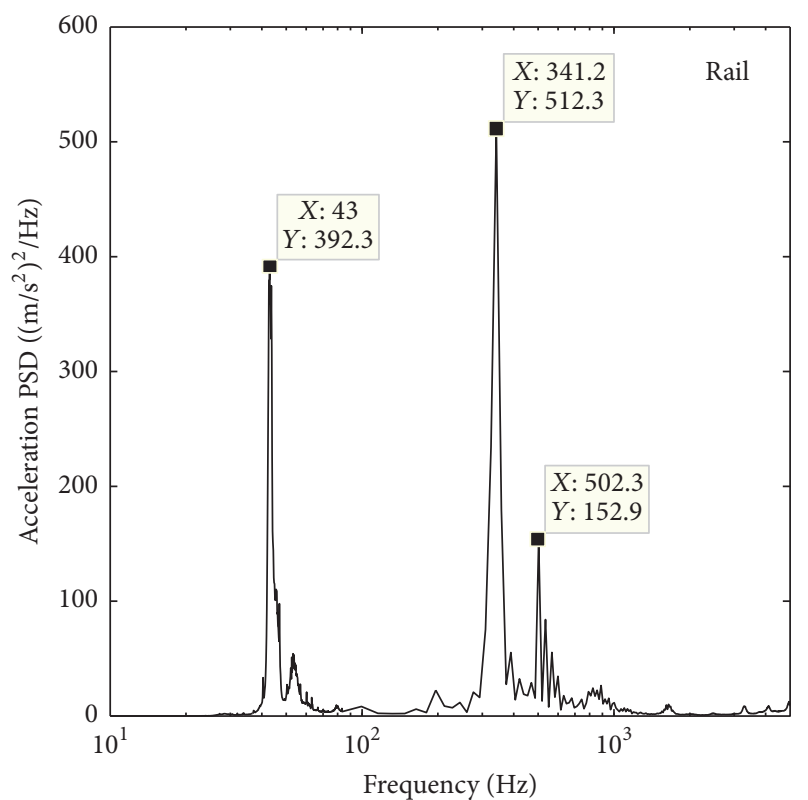

FIGURE 7: The acceleration power spectrum of the rail.

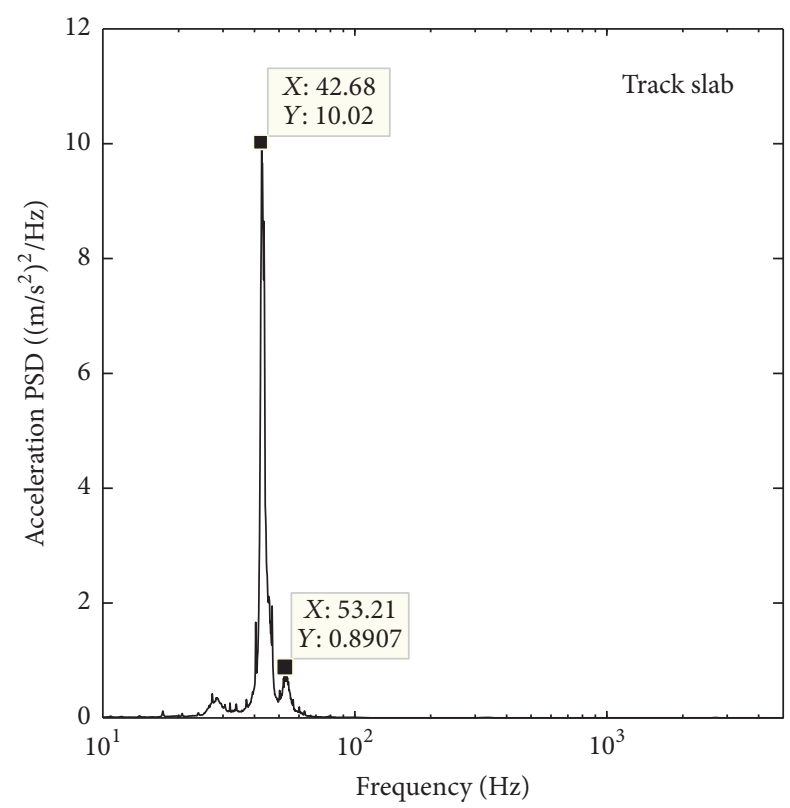

FIGURE 8: The acceleration power spectrum of the track slab.

$0.24 \mathrm{~m}$, and $0.17 \mathrm{~m}$ under the train running at the speed of $300 \mathrm{~km} / \mathrm{h}$. From Figure 8, it can be seen that the vibration acceleration power spectrum density of the slab caused by track random irregularity has two obvious peaks in the range of $30 \sim 100 \mathrm{~Hz}$, respectively, at $42.6 \mathrm{~Hz}$ and $53.2 \mathrm{~Hz}$, where the corresponding wavelength is, respectively, $2 \mathrm{~m}$ and $1.6 \mathrm{~m}$ under the train running at the speed of $300 \mathrm{~km} / \mathrm{h}$. From Figure 9, it can be seen that, very similar to that of the slab in Figure 11, the vibration acceleration power spectrum density of the subgrade caused by track random irregularity has two obvious peaks in the range of $30 \sim 100 \mathrm{~Hz}$, respectively, at

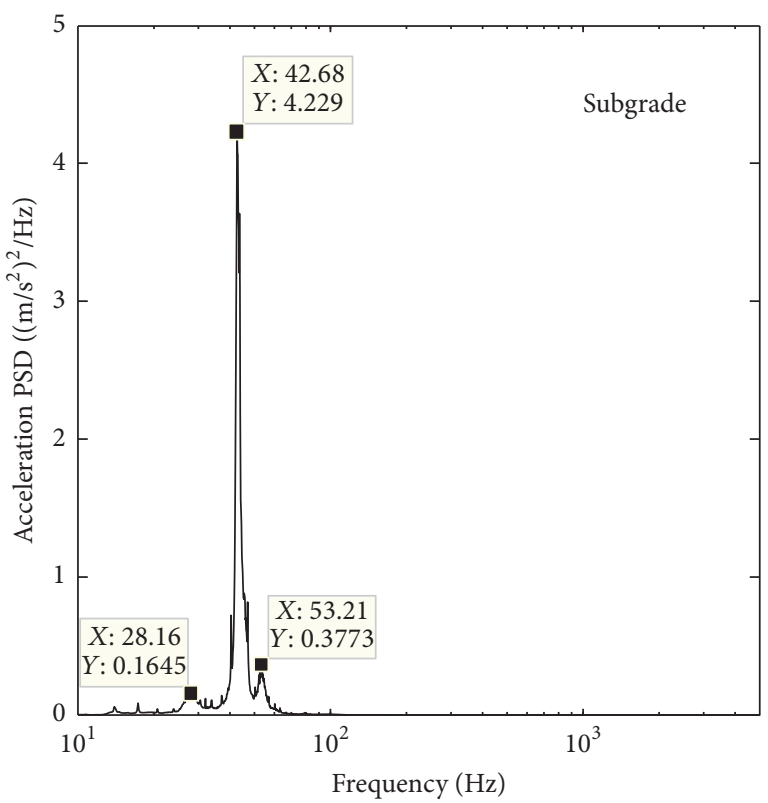

FIGURE 9: The acceleration power spectrum of the subgrade.

42.6 Hz and $53.2 \mathrm{~Hz}$, where the corresponding wavelength is, respectively, $2 \mathrm{~m}$ and $1.6 \mathrm{~m}$ under the train running at the speed of $300 \mathrm{~km} / \mathrm{h}$. From Figures 7-9, it can also be seen that all of the vibration acceleration power spectrum density of rail, slab, and subgrade have a main peak value around $43 \mathrm{~Hz}$, mainly due to the fact that the track irregularity has excitation wavelength in this band, as is shown in Figure 5; another main frequency of rail is induced by the shortwave irregularity, wavelength below $1 \mathrm{~m}$, in the rail surface; in addition, the frequency band of the vibration energy spectrum of the rail is wider than that of the slab and subgrade, and the frequency band of the vibration energy spectrums of slab and subgrade is mainly concentrated in the low frequency around $43 \mathrm{~Hz}$.

\subsection{The Influence of ACL's Stiffness on the Vibration Power of} Track and Subgrade System. In order to reflect the vibration transfer characteristics of track-subgrade coupling system, the vibration power flow theory is used to analyze the vibration transfer characteristics of ballastless track-subgrade coupling system. The average value of track-subgrade system vibration power during a period is given by

$$
P=\frac{\int_{0}^{T} F(t) V(t) d t}{T},
$$

where $P$ is the average power; $F(t)$ is the external force applied at the track-subgrade system, and $V(t)$ is the vibration velocity in time domain. And the vibration power in frequency domain can be written as

$$
P(\Omega)=\frac{1}{2} \operatorname{Re}\left\{F^{*}(\Omega) V(\Omega)\right\},
$$

where $F^{*}(\Omega)$ is the conjugated matrix of the force amplitude matrix and $V(\Omega)$ is the vibration velocity in frequency domain. Vibration power of track-subgrade system is 


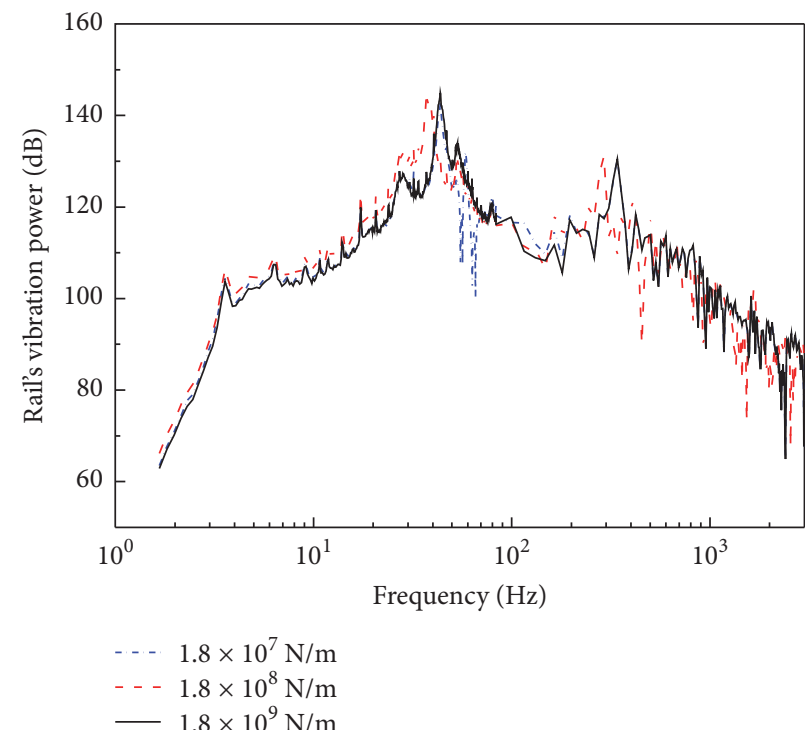

(a) Rail

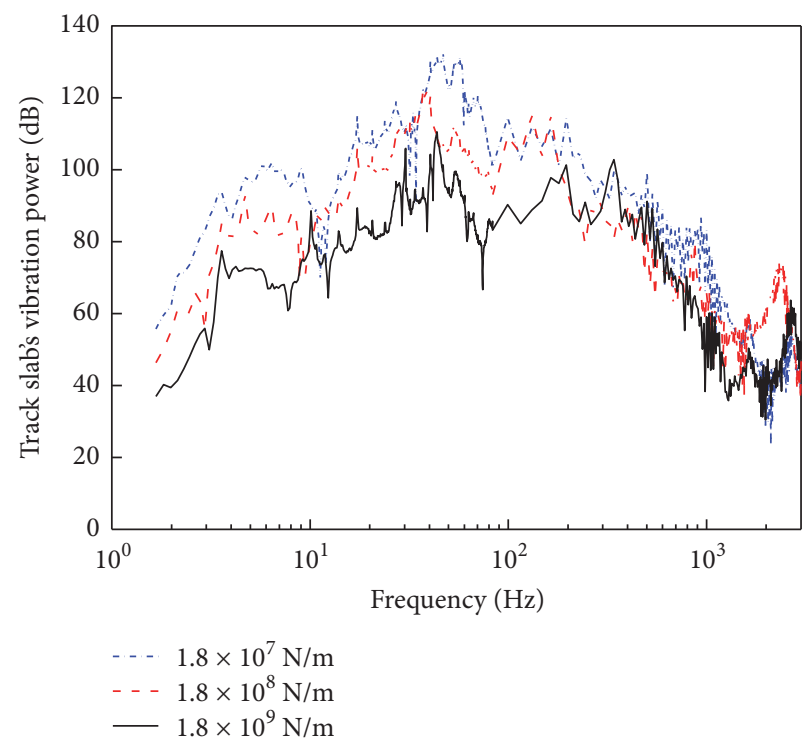

(b) Slab

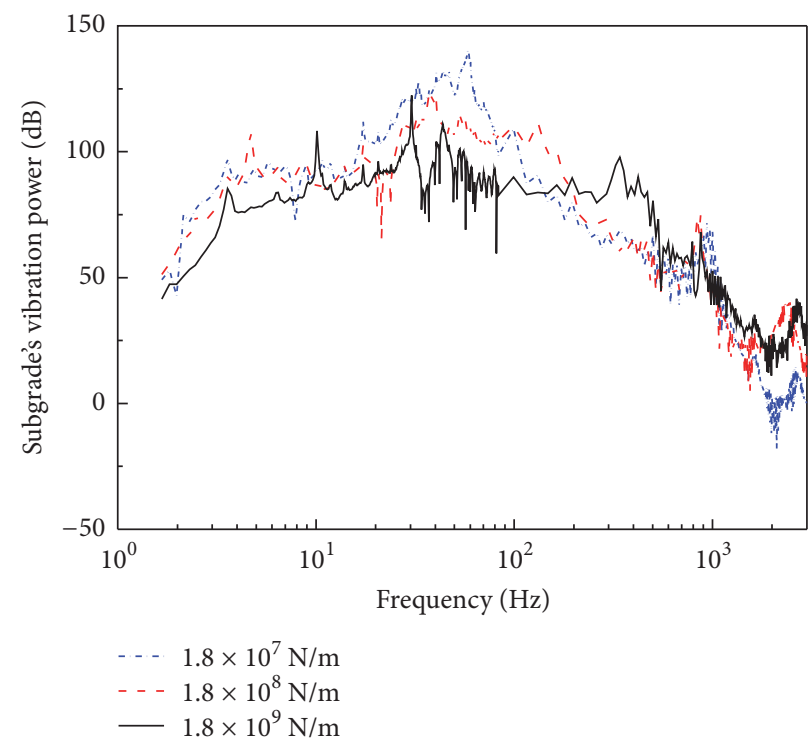

(c) Subgrade

FIGURE 10: The effect of ACL's stiffness on the vibration power of track and subgrade system.

expressed by the power level, and reference vibration power is $10^{-12} \mathrm{~W}$.

ACL has an important influence on vibration-reduction of track-subgrade coupling system. In order to reflect the effect of ACL's stiffness on subgrade vibration-reduction, stiffness parameters of three ACL are $1.8 \times 10^{7} \mathrm{~N} / \mathrm{m}, 1.8 \times$ $10^{8} \mathrm{~N} / \mathrm{m}$, and $1.8 \times 10^{9} \mathrm{~N} / \mathrm{m}$, respectively. Figure 10 shows the impact of ACL's stiffness on the vibration power of track and subgrade coupling system. The other parameters are unchangeable.

It can be seen from Figure 10 that, for the rail, the influence of ACL's stiffness on rail vibration at $100 \sim 150 \mathrm{~Hz}$ is more than that at the other frequencies. For the track slab, the larger the stiffness of ACL, the lower the vibration power of the track bed at $1 \sim 1800 \mathrm{~Hz}$. When the stiffness of ACL increases by ten times, the vibration power of the slab will decrease by about $20 \mathrm{~dB}$. For the subgrade, the larger the stiffness of ACL, the lower the vibration power of the subgrade bottom and the lower the peak frequency of subgrade below $100 \mathrm{~Hz}$. The larger the stiffness of ACL, the higher the peak frequency of subgrade at $100-700 \mathrm{~Hz}$. The vibration power of the subgrade increases with the stiffness of ACL above $1000 \mathrm{~Hz}$. It can be concluded that some peaks in Figure 10 relate to nature frequencies of track-subgrade system and track random irregularities.

3.4. The Influence of Train Speed on the Track and Subgrade System Vibration Power. To investigate the impact of train speed on the track and subgrade system vibration power, the train speeds are, respectively, $100 \mathrm{~km} / \mathrm{h}, 200 \mathrm{~km} / \mathrm{h}, 300 \mathrm{~km} / \mathrm{h}$, 


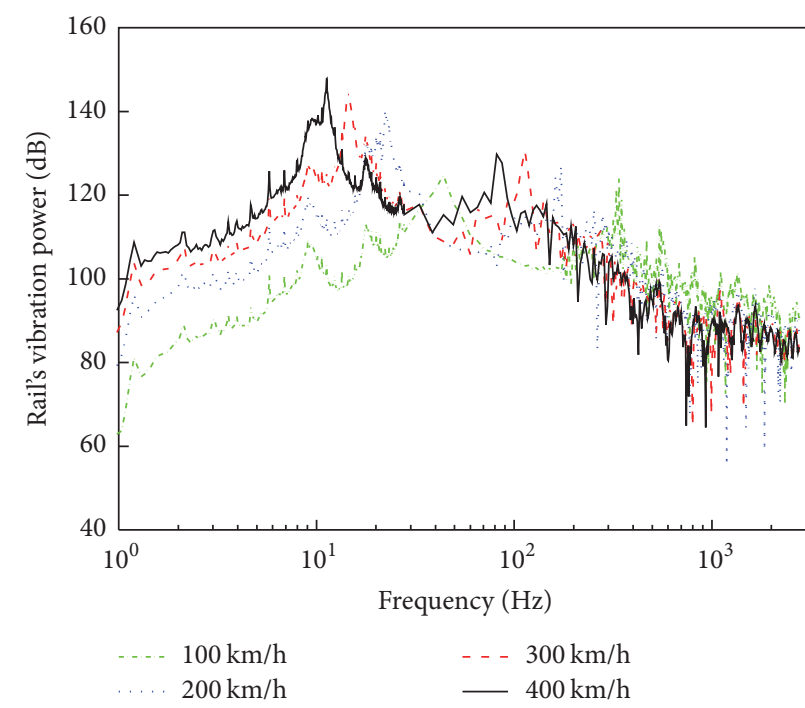

(a) Rail

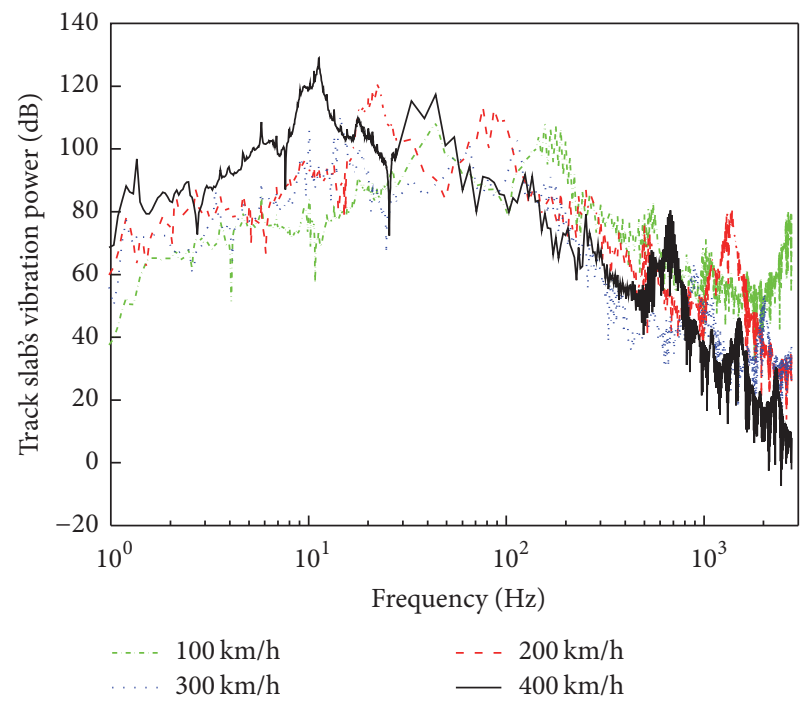

(b) Slab

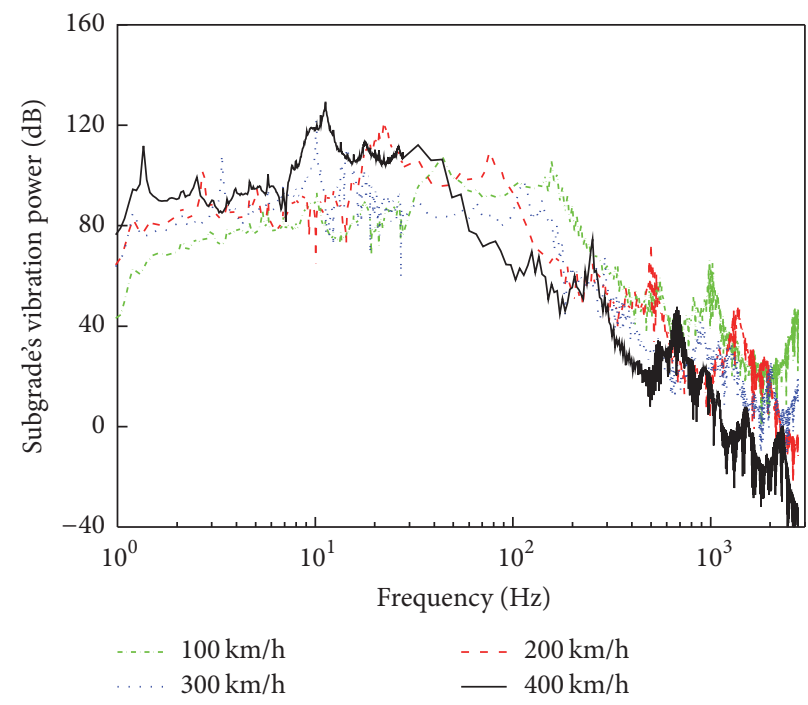

(c) Subgrade

FIGURE 11: The effect of vehicle speed on the vibration power of track and subgrade system.

and $400 \mathrm{~km} / \mathrm{h}$. Figure 11 shows the influence of train speed on the vibration power of the track and subgrade system.

It can be seen from Figure 11 that when the train speed is $400 \mathrm{~km} / \mathrm{h}$ under excitation of track random irregularities, the vibration power of track-subgrade coupling system has maximum peak at about $40 \mathrm{~Hz}$, and the maximum of vibration power of the rail, bed slab, and subgrade reaches $150 \mathrm{~dB}$, $130 \mathrm{~dB}$, and $125 \mathrm{~dB}$, respectively. Figure 11 also indicates that the higher the train speed, the larger the amplitude of resonance peak of the track-subgrade vibration power but the lower the frequency of resonance peak of them.

\section{Conclusions}

In order to reduce the ground-borne vibration caused by wheel/rail interaction in the ballastless track of high speed railways, viscoelastic asphalt concrete materials are filled between the track and the subgrade to attenuate wheel/rail force. In combination with double-block ballastless track and subgrade structure characteristics, considering the finite length and discontinuity of the monolithic slab, discreteness of the pads under rail, and the continuity of subgrade, a high speed train-track-subgrade vertical coupling dynamic model is developed and the analytic expressions of vibration response are also derived. Combined with the pseudoexcitation method, a solution of the dynamic response is put forward to calculate the receptance of ballastless track and subgrade system. The random vibration response and transfer characteristics of ballastless track and subgrade system are obtained under track random irregularity when a high speed vehicle runs through. We can conclude the following:

(1) The peak frequencies of the results of the proposed model are basically consistent with those of finite element method. 
(2) The frequency band of the vibration energy spectrum of rail is wider than that of the slab and subgrade, and the frequency band of the vibration energy spectrums of slab and subgrade is mainly concentrated in the low frequency around $43 \mathrm{~Hz}$.

(3) The stiffness of ACL has relatively less influence on rail vibration than on the ballast bed and subgrade vibration.

(4) The higher the train speed, the larger the amplitude of resonance peak of the track-subgrade vibration power but the lower the frequency of resonance peak of them.

\section{Competing Interests}

The authors declare that they have no competing interests.

\section{Acknowledgments}

This research was supported by National Natural Science Foundation of China (nos. 51165017, 51268030, and 51378395) and Open Fund of Traction Power State Key Laboratory, Southwest Jiaotong University (Grant no. TPL1602).

\section{References}

[1] K. Knothe, "Past and future of vehicle/track interaction," Vehicle System Dynamics (Supplement), vol. 45, no. 24, pp. 1-3, 1995.

[2] S. L. Grassie, "Review of workshop: aims and open questions," Vehicle System Dynamics (Supplement), vol. 45, no. 24, pp. 380386, 1995.

[3] V. V. Krylov, "Generation of ground vibrations by superfast trains," Applied Acoustics, vol. 44, no. 2, pp. 149-164, 1995.

[4] A. Matsuura, "Impulsive response of an elastic layered medium in the anti-plane wave field based on a thin-layered element and discrete wave number method,' Structural Engineering/ Earthquake Engineering, vol. 9, no. 22, pp. 119-128, 1993.

[5] A. Matsuura, "Simulation for analyzing direct derailment limit of running vehicle on oscillating tracks," Structural Engineering/Earthquake Engineering, vol. 15, no. 1, pp. 63-72, 1998.

[6] A. M. Kaynia, C. Madshus, and P. Zackrisson, "Ground vibration from high-speed trains: prediction and countermeasure," Journal of Geotechnical and Geo-environmental Engineering, vol. 126, no. 6, pp. 531-537, 2000.

[7] H. Takemiya, "Simulation of trackground vibrations due to high-speed trains," in Proceedings of the 8th International Congress on Sound and Vibration, pp. 2875-2882, Hong Kong, 2001.

[8] C. Madshus and A. M. Kaynia, "High-speed railway lines on soft ground: dynamic behaviour at critical train speed," Journal of Sound and Vibration, vol. 231, no. 3, pp. 689-701, 2000.

[9] Q. Su and Y. Cai, "A spatial time-varying coupling model for dynamic analysis of high speed railway subgrade," Journal of Southwest Jiaotong University, vol. 36, no. 5, pp. 509-513, 2001.

[10] L. Dong, C.-G. Zhao, D.-G. Cai, Q.-L. Zhang, and Y.-S. Ye, "Method for dynamic response of subgrade subjected to highspped moving load," Engineering Mechanics, vol. 25, no. 11, pp. 231-240, 2008 (Chinese).

[11] B. Liang, H. Luo, and C.-X. Sun, "Simulated study on vibration load of high speed railway," Journal of the China Railway Society, vol. 28, no. 4, pp. 89-94, 2006 (Chinese).
[12] X.-N. Ma, B. Liang, and F. Gao, "Study on the dynamic properties of slab ballastless track and subgrade structure on highspeed railway," Journal of the China Railway Society, vol. 33, no. 2, pp. 72-78, 2011 (Chinese).

[13] Q.-Y. Xu, Y.-F. Cao, and X.-L. Zhou, "Influence of short-wave random irregularity on vibration characteristic of train-slab track-subgrade system," Journal of Central South University, vol. 42, no. 4, pp. 1105-1110, 2011 (Chinese).

[14] P. Xu and C.-B. Cai, "Spatial dynamic model of train-ballast track-subgrade coupled system," Engineering Mechanics, vol. 28, no. 3, pp. 191-197, 2011 (Chinese).

[15] J. Li and K. Li, "Finite element analysis for dynamic response of roadbed of high-speed railway," Journal of the China Railway Society, vol. 17, no. 1, pp. 66-75, 1995.

[16] C.-J. Wang and Y.-M. Chen, "Analysis of stresses in traininduced ground," Chinese Journal of Rock Mechanics and Engineering, vol. 24, no. 7, pp. 1178-1187, 2005.

[17] W. M. Zhai, Vehicle-Track Coupled Dynamics, Science Press, Beijing, China, 2007.

[18] H. Liu, A Study on Modelling, Prediction and Its Control of Wheel/Rail Rolling Noises in High Speed Railway, Shanghai Jiaotong University, Shanghai, China, 2010.

[19] H. Wei, Elevated Track Structure Vibration and Transmitting Characteristics of Urban Mass Transit, Tongji University, Shanghai, China, 2012.

[20] J. H. Lin and Y. H. Zhang, Pseudo Excitation Method in Random Vibration, Science Press, Beijing, China, 2004.

[21] F. Lu, Q. Gao, J. H. Lin, and F. W. Williams, "Non-stationary random ground vibration due to loads moving along a railway track," Journal of Sound and Vibration, vol. 298, no. 1-2, pp. 3042, 2006.

[22] J. H. Lin, Y. H. Zhang, and Y. Zhao, "Pseudo excitation method and some recent developments," Procedia Engineering, vol. 14, pp. 2453-2458, 2011.

[23] C. C. Caprani, "Application of the pseudo-excitation method to assessment of walking variability on footbridge vibration," Computers \& Structures, vol. 132, pp. 43-54, 2014. 


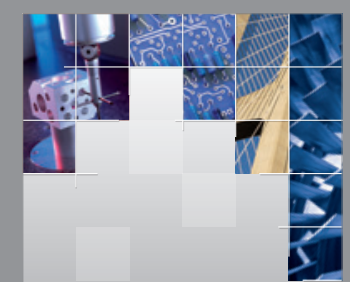

\section{Enfincering}
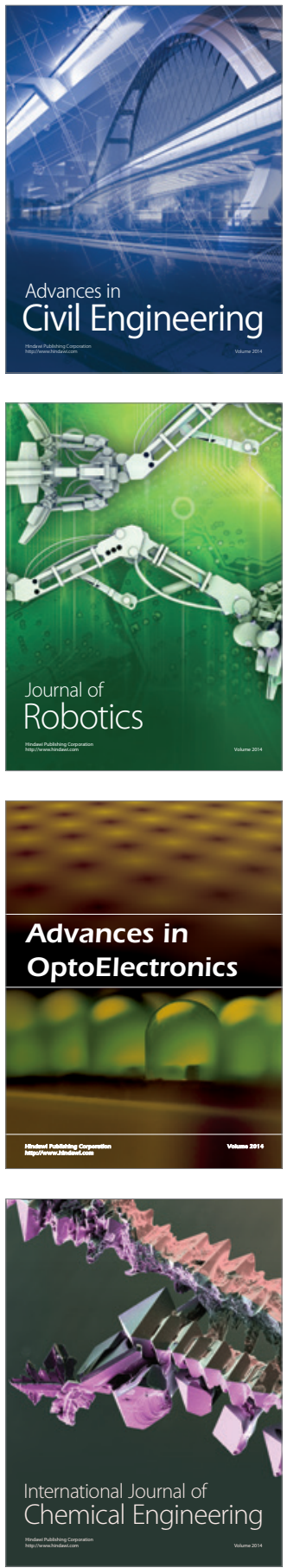

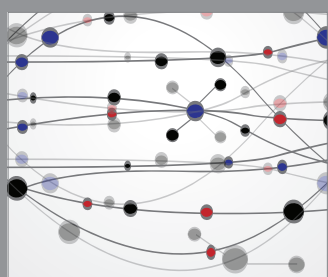

The Scientific World Journal

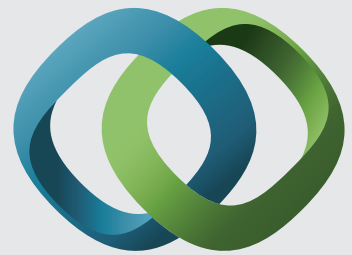

\section{Hindawi}

Submit your manuscripts at

http://www.hindawi.com
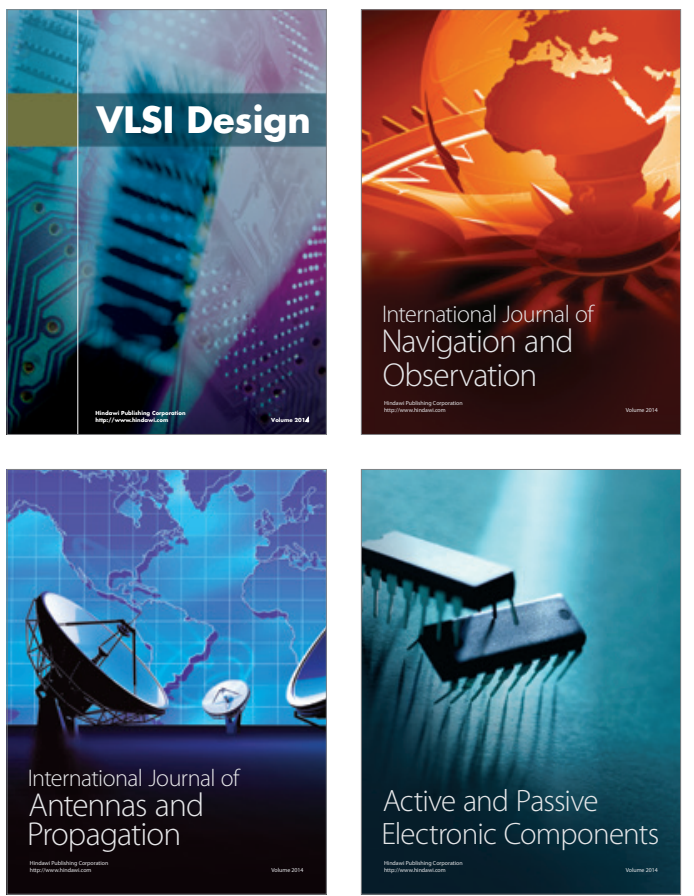
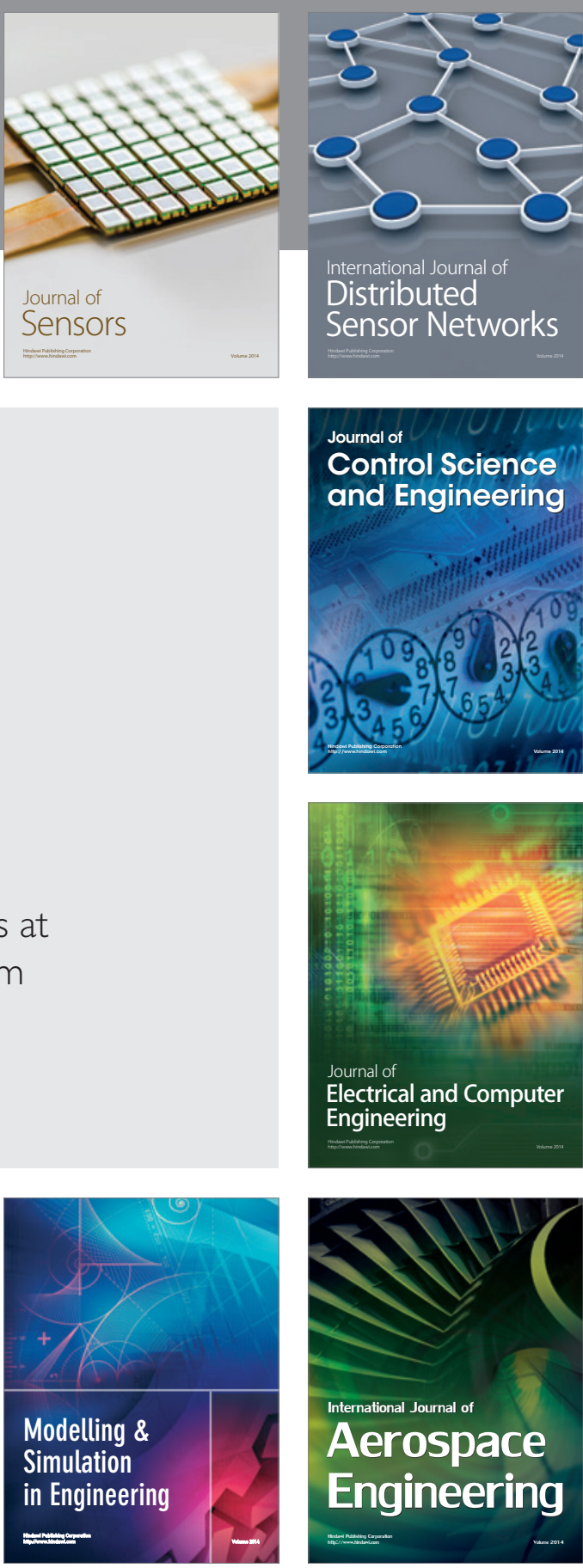

International Journal of

Distributed

Sensor Networks

Journal of

Control Science

and Engineering
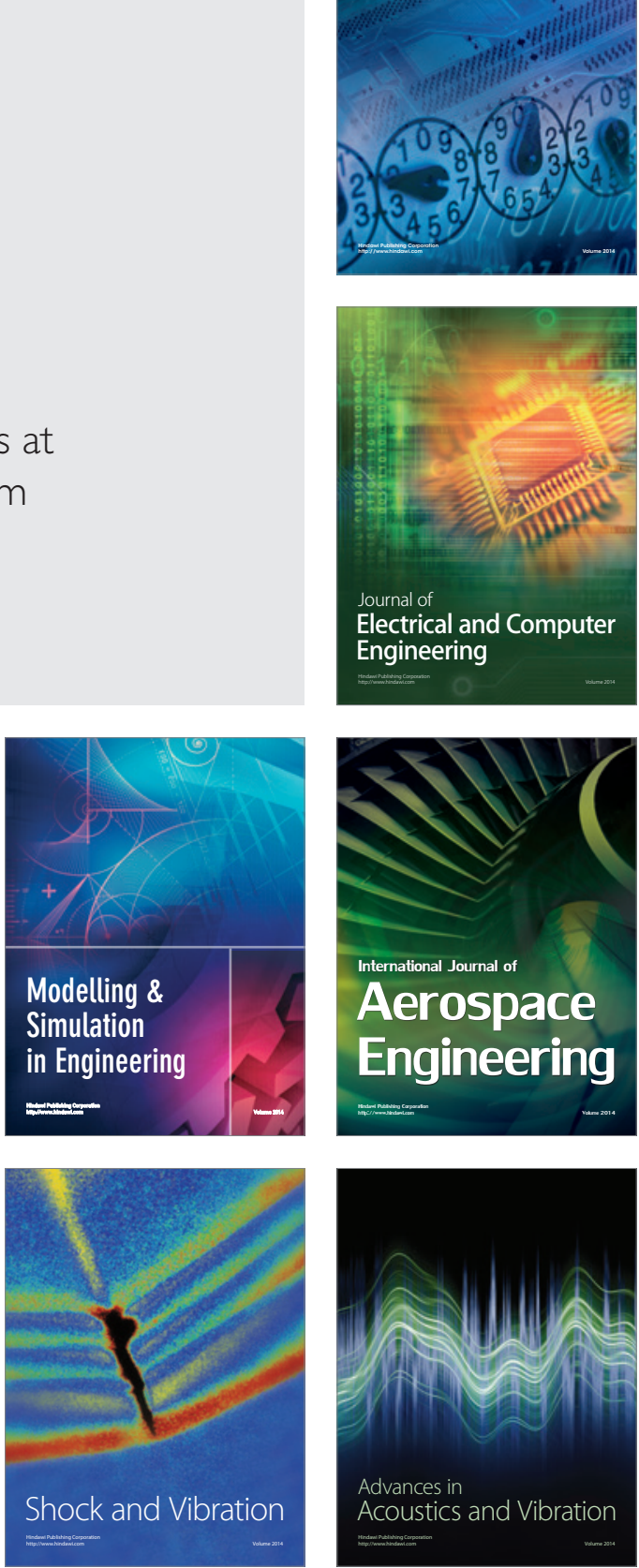